\title{
Risk assessment methodology for paste and thickened tailings
}

\author{
A Fernandez-Iglesias ArcelorMittal Global R\&D Asturias, Spain \\ A Correa ArcelorMittal Mining, France \\ O Morton ArcelorMittal Mining, UK \\ J Laine University of Oviedo, Spain \\ R Luiña University of Oviedo, Spain \\ G Martínez University of Oviedo, Spain
}

\begin{abstract}
According to the database compiled by the US Commission on Large Dams (USCOLD) and completed later by the International Commission on Large Dams (ICOLD) and the US Environmental Protection Agency (EPA), there have been two or more major tailing dam failure incidents per year between 1970 and 2000, proving that these catastrophic failure events are not rare occurrences.
\end{abstract}

Paste and thickened tailings (P\&TT) technology has emerged in recent years as a promising technique to avoid dam incidents. Due to the low water content of the $P \& T$, the potential for liquefaction is reduced drastically in comparison to conventional tailing dams. This is one of the major advantages of the technology, alongside the volume reduction and the absence of bleed water. However, paste also has some drawbacks such as higher energy consumption and extra equipment requirements.

Due to these advantages and drawbacks, a set of different tools is required to assess the feasibility of a paste facility at a specific mine. Among these tools, those related to risk become important since one of the major advantages of paste is related to this dimension. Thus, selecting the right tool for analysis is a key factor in the decision-making process that may lead to the selection of P\&TT as an alternative to conventional tailings storage.

According to the AS/NZS 4360:2004 'Risk Management' (Standards Australia 2004), developing a risk assessment involves a three-stage process: identify, analyse and evaluate all the risks involved. The best tool to provide structure for these stages is a failure modes and effect analysis (FMEA) of the tailings system.

In the present work, a general comparison between P\&TT and conventional tailings storage has been made in terms of risk, using a FMEA based on a classification of likelihood and consequences in a semi-quantitative risk assessment. All risks for stages from the concentration plant onwards are considered for each scenario, in two different categories: environmental and public safety.

Paste and thickened tailings technology has more risks classifying as low to moderate than conventional tailings and has less risks classifying as moderate to high area. These results can be used as an indication of the sustainability of P\&TT disposal in terms of risks. Although the goal of the study is to make a general comparison not applied to any specific mine, it can also be used as a methodology or template for a risk assessment for any existing installation.

\section{Introduction}

Exploitation of mineral resources is a very important activity for the development of society, but at the same time, mining has acquired a negative reputation owing to the negative impacts associated with contamination and structural failures (Dold 2008). The main environmental problem that the mining 
industry faces is derived from tailings because of the volume generated and the contaminants associated with the tailings.

Among different tailings storage techniques, the most common one is conventional impoundment storage. The main part of conventional impoundments is an embankment to retain the tailings and water (Engels 2013). The failure of these embankments is the main reason of catastrophic damage to the environment and the public and even loss of life during operation and in the after-care phase (European Neighbourhood Partnership Instrument (Eastern Region) [ENPI East] 2011).

Many databases have been established to record the dam failures all around the world. In 1994, USCOLD developed a database of 185 incidents related to tailing dams between 1913 and 1989. The International Commission on Large Dams and the US Environmental Protection Agency (US EPA) added more recently. From the database, it can be concluded that from 1970-2000, there have been approximately two to five 'major' tailings dam failure incidents per year. During no year were there less than two events (1970-1999, inclusive) (Davies et al. 2000). This proves that mine tailings spills are not rare occurrences and may happen on all continents and countries where there is mining (Robinsky 1999).

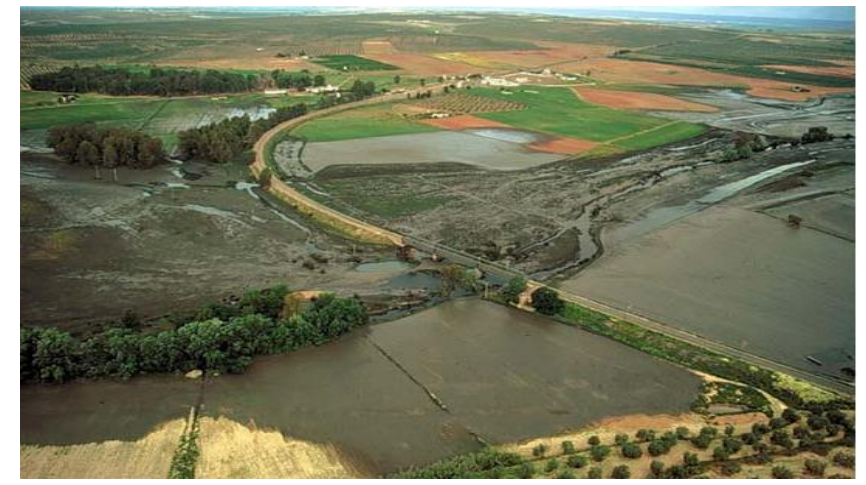

Figure 1 Contaminated spill in Aznalcóllar, Spain (Aguilar 2000)

These incidents have elevated the public concern about the environmental and public impacts of the mining industry. The global requirements for sustainable development also urge the mining industry to meet the challenge of sustainability, which presents a variety of risks (and opportunities) for the minerals industry (RET 2008).

One possible solution to reduce the incidence of failures is the application of a paste or thickened tailings disposal management strategy. Multiple analyses have been done on these systems from the environmental and economic point of view, using lifecycle assessment and costs analysis.

Due to the importance shown by the failure events recorded in the databases, it is clear that the benefits of P\&TT linked to risk reduction should be taken into account during decision making processes. Evaluating the risks will also help rating the feasibility of a thickened tailings system.

Risk analysis facilitates the quantification of options, likelihood, consequences and costs of failure. The 'risk' rating is obtained from the qualitative product of the likelihood and consequence (RET 2007). 


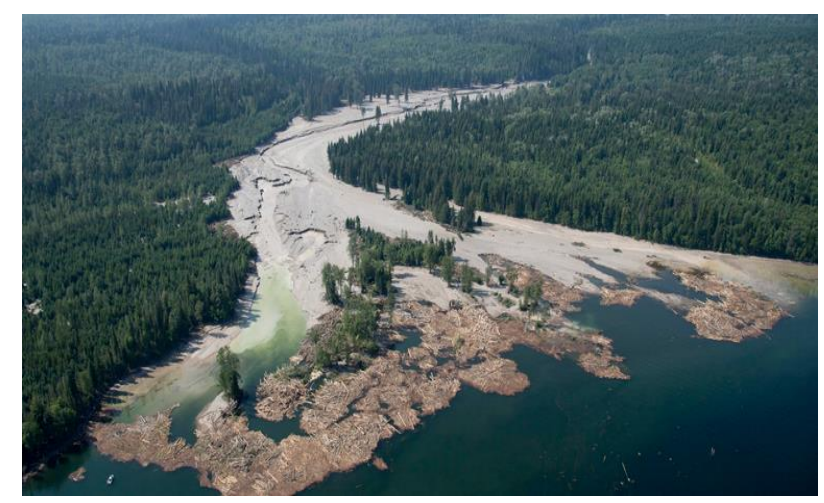

Figure 2 Spill in Mount Polley, Canada

A range of methodologies are available from qualitative, semi-quantitative to quantitative approaches (RET 2008). The minerals industry safety and health risk management guideline outlines the following risk assessment techniques (RET 2008):

- Informal risk assessment (IRA).

- Job safety/hazard analysis (JSA/JHA).

- Energy barrier analysis (EBA).

- Preliminary hazard analysis/hazard analysis/workplace risk assessment and control (PHA/HAZAN/WRAC); hazard and operability study (HAZOP).

- Fault tree analysis (FTA).

- Failure modes, effects and criticality analysis (FMECA).

\subsection{Risk assessment in the mining industry}

There are many studies about the risk assessment methodology applied to the mining industry, such as the handbook of the Australian Government, 'Risk assessment and management', which aims to identify the key issues affecting sustainable development and provides information and case studies to illustrate a more sustainable basis for the mining industry (RET 2008). The European Neighborhood Partnership Instrument (EMPI) also developed the 'Methodology for the Environmental and Health Risk Assessment of Mine Tailings Disposal Sites' in 2011. The goal of this study was to find solutions that identify and deal with risks from mine tailings contamination in a sustainable way, providing general guidance on conducting risk assessment for tailings and similar sites (ENPI East 2011).

There are also many case studies about risk assessment of tailing dams, such as the risk evaluation system developed by Xin, which is based on tailings dam failure probability analysis and consequence assessment (Xin 2011). Robertson and Shaw developed a risk management methodology for major geotechnical structures on mines (2009). The study of Xenidis identifies the specific risks associated with the carbonate wastes and determines the remedial measures required by combing the available geochemical characterisation techniques and risk assessment tools (Xenidis et al. 2003).

The cited references prove the reliability of the methodologies and their application; however, most are focused on one case only, which is usually the failure of the tailings storage facility during the operational stage, and do not contain information about post-closure stages. There are few references that compare the different tailings disposal methods through all stages of the lifecycle using risk assessment and none are focused on Paste technology.

In the present paper a risk assessment methodology in the form of a failure modes and effect analysis (FMEA) is described and applied to two different scenarios: conventional and thickened tailings storage facilities. 


\section{$2 \quad$ Methodology}

\section{$2.1 \quad$ Risk assessment}

The process of assessing and managing risks is aimed at identifying priority risks which require a reduction in either likelihood or consequence and at increasing the likelihood and impact of positive outcomes. (RET 2008). AS/NZS 4360:2004 recommends the following risk assessment process (RET 2007):

- Establish the context. Geographically, socially and environmentally, and decide on the design criteria.

- Identify the hazards. What can happen, where, when, how and why.

- Analyse the risks. Identify existing controls, determine the likelihoods and consequences, and hence the level of risk.

- Evaluate the risks. Compare them against the design criteria, carry out sensitivity analyses to highlight both the key and unimportant risks, set priorities, and decide whether the risks need to be addressed.

- Address the selected risks. Identify and assess options, prepare and implement treatment plans, and analyse and evaluate the residual risk.

The specific tool used to perform this analysis is the FMEA.

\subsection{Failure modes and effect analysis}

FMEA was one of the first used systematic techniques for failure analysis. It was developed by reliability engineers in the 1950s to study problems that might arise from malfunctions of military systems. A FMEA is often the first step of a system reliability study. It is mainly a qualitative process and involves reviewing as many components, assemblies and subsystems as possible to identify failure modes, their causes and effects (Rausand 2003).

Failure modes are the core element of the FMEA. A failure mode can be naturally initiated (e.g. an earthquake that is greater than the design event), initiated by the failure of one of the engineered subsystems (e.g. instability of a dam), or be a result of operational failure (e.g. failure to close a valve releasing contaminating fluids). Because of the large number of potential failure modes that could be included in an FMEA, it is often necessary to confine evaluations to those that represent a significant risk. Failure modes can also be combinations of events where a small trigger event sets off a chain of events resulting in substantial or large consequences (Robertson \& Shaw 2003).

This type of FMEA is a top down expert system approach to risk identification and quantification leading to mitigation measure identification and prioritisation. Its value and effectiveness depends on having experts with the appropriate knowledge and experience participating in the failure modes evaluation, risk estimation, and identification of the appropriate mitigation measures (Robertson 2014). The stages set out below are similar to those used for general risk assessment (RET 2007).

- Stage 1: Identify all significant failure modes.

- Stage 2: Assess likelihood and effects (consequences) of every failure mode.

○ Environmental impact.

○ Public safety.

- Stage 3: Assess the severity of effects and level of confidence of every failure modes.

- Stage 4: Identify mitigation measures that will reduce risks to tolerable limits.

The FMEA can be used to evaluate the potential for failures of operational and closure related measures that could result in biological impacts, land use impacts, regulatory impacts, public concern or image 
impacts and health and safety Impacts. A risk profile can thus be developed for each of these areas of concern. Once the failure modes and measures with the highest risk have been identified, it is possible to consider mitigation or alternative designs to reduce risks. FMEAs are therefore an essential part of any risk and liability reduction program (Robertson \& Shaw 2003). 


\subsubsection{Stage 1: Identify all significant failure modes}

The failure modes in this research are based on Bulletin 121 (International Commission on Large Dams \& United Nations Environmental Programme 2001) of the International Commission on Large Dams (ICOLD), and experts consulting in the fields of geotechnics, hydrology, environmental impacts, regulatory requirements applicable to the engineered and natural systems and their surroundings, and mining design and operations. Failure modes are identified for all system components including the following:

- Failure of pipeline transportation and pumping (pipe plugging, pipe breakage, pump breakage).

- Failure of the storage facility during operation and post-closure stage (dam liquefaction, slumping or toe failure, failure of exposed tailings face, overtopping, seepage, dust generation etc.).

- Failure of the thickener (operational failure, underflow exit plugging, rakes jamming or breakage).

\subsubsection{Stage 2: Assess likelihood and effects (consequences) of every failure mode}

The likelihood of the failure mode leading to the effect has been classified using a five-class system, ranging from 'not likely' to 'expected'.

Table 1 Likelihood of event (Robertson \& Shaw 2003)

\begin{tabular}{ccc}
\hline Likelihood & As a percentage & As a statistical number \\
\hline Not likely (NL) & $<0.01 \%$ & $<1: 10,000$ \\
Low (L) & $0.01 \%-0.1 \%$ & $1: 10,000-1: 1,000$ \\
Moderate (M) & $0.1-1 \%$ & $1: 1,000-1: 100$ \\
High (H) & $1-10 \%$ & $1: 100-1: 10$ \\
Expected (E) & $>10 \%$ & $>1: 10$ \\
\hline
\end{tabular}

\subsubsection{Stage 3: Assess the severity of effects and level of confidence of every failure modes}

The assessment of the effects (or consequences) of specific failure modes is based on the evaluations or analyses of the systems responses following failure. These effects may have physical, biological or health and safety consequences. Each effect will be assessed separately in two concern areas:

- Environmental impacts

- Public safety

The consequence ranking, or severity, is typically also classified using a five-category system. Past researchers have found ranking from 'negligible' to 'extreme' consequences to be effective and intuitive. The class intervals for each of the categories are outlined in Table 3. Again, these are suggested classifications that have been found useful in the past, but could be adapted to best suit the site or plan being evaluated at the time (Robertson \& Shaw 2003). 
Table 2 Severity of effects (Robertson \& Shaw 2003)

\begin{tabular}{|c|c|c|}
\hline Severity & Environmental impact & Public safety consequences \\
\hline Extreme (E) & $\begin{array}{l}\text { Catastrophic impact on habitat } \\
\text { (irreversible and large) }\end{array}$ & Fatality or multiple fatalities expected \\
\hline High $(H)$ & $\begin{array}{l}\text { Significant, irreversible impact on } \\
\text { habitat or large, reversible }\end{array}$ & $\begin{array}{l}\text { Severe injury or disability likely; or some potential } \\
\text { for fatality }\end{array}$ \\
\hline Moderate (M) & $\begin{array}{c}\text { Significant, reversible impact on } \\
\text { habitat }\end{array}$ & $\begin{array}{l}\text { Lost time or injury likely; or some potential for } \\
\text { serious injuries; or small risk of fatality }\end{array}$ \\
\hline Low (L) & Minor impact on habitat & First aid required; or small risk of serious injury \\
\hline Negligible (N) & No measurable impact & No concern \\
\hline
\end{tabular}

\subsubsection{Stage 4: Identify mitigation measures that will reduce risks to tolerable limits}

There is uncertainty regarding both the likelihood of failure and the consequence based on a number of factors, including lack of data, lack of system understanding, uncertain future operating conditions or uncertain maintenance. Thus, confidence in the risk estimates may range from low to high (Robertson \& Shaw 2003). According to Robertson GeoConsultants Inc (Sachan 2010), three interval classification system of low, medium and high confidence in the risk ratings is usually adequate and appropriate. Where there is low confidence in a high risk assessment value, this clearly indicates a need to further evaluate the risk in order to get a more reliably prediction of both the risk and the mitigation measures to reduce such risk (Robertson \& Shaw 2003). In this research, we will use the three interval classification.

Table 3 Level of confidence (Robertson \& Shaw 2003)

\begin{tabular}{cc}
\hline Confidence level & Description \\
\hline Low (L) & Do not have confidence in the estimate or ability to control during operations, or \\
post-closure
\end{tabular}

\subsubsection{Limitations}

As there are many different risks, only the most common and important risks under the experts considerations will be taken into account.

As paste is a new and developing tailings disposal method, there are limited failures, accidents and data available to verify the nature and frequency of incidents.

Since FMEA is effectively dependent on the members of the committee which examines product failures, it is limited by their experience of previous failures or general knowledge of failure mechanisms and modes.

Risk assessment is site specific. As such the risks are highly dependent on the site's location, geography, climate, regulation, the tailings' category and other parameters. The study could only focus on the most common risks and considerations, so for each specific case, detailed field study is needed to evaluate the risks more comprehensively. 


\subsection{Scenarios}

Failure mode and effects analysis will be the methodology used, developed and described for two process stages: Operations (OP), through to the end of the mine's operating life for an assumed period of 30 years (Doka 2009); and post-closure (PC), for a 100-year period following the implementation of the closure plan (Doka 2009).

\subsubsection{Scenario 1: conventional tailings storage facility}

The tailings slurry is discharged with a considerable amount of process water (20\% solids concentration) into the tailings storage facility. Supernatant water is reclaimed from the pond surface and pumped back to the plant. Upstream rising is assumed. During and after the operation, a vegetation cover will be established.

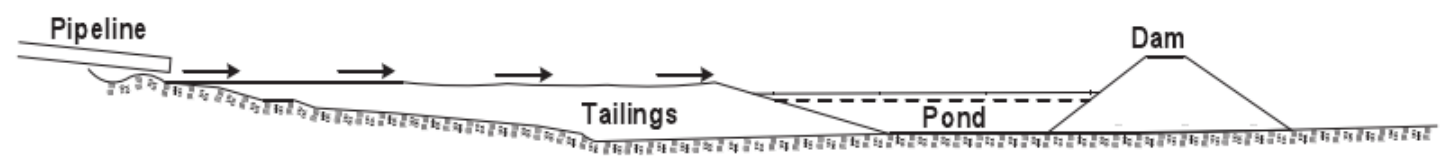

Figure 3 Conventional tailings disposal system (Wennberg 2010)

\subsubsection{Scenario 2: paste tailings}

The tailings slurry is thickened from $20-60 \%$ solids concentration before discharge into a storage facility. An even beach slope of $2 \%$, with no segregation and virtually no bleed water has been assumed (Wennberg 2010). The thickener water overflow is assumed to be retained within the plant circuit.

Process water is retained at the plant. Rain water and seepage is returned to the plant by a relatively small pumping station. Tailings are discharged from a constructed artificial ramp or tower, resulting in a ridge or cone of tailings. A low perimeter dyke is required to collect direct precipitation and a small amount of process bleed water and to direct it to a pond, ideally located beyond the limits of the tailings deposit.

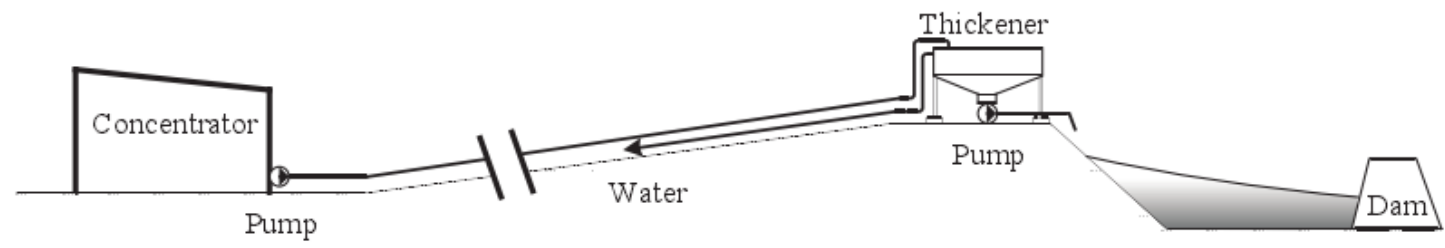

\section{Figure 4 Thickened tailings system with thickener located by disposal area (Wennberg 2010)}

\section{$3 \quad$ Results}

The following tables and figures summarise the FMEA results.

\subsection{Risk assessment of conventional and paste tailings: scenarios comparison}

In Table 4, all the failure modes evaluated in this study are described and assigned an ID number. They cover all of the potentially significant failure modes in each of the described scenarios. 


\section{Table 4 Description and ID of failure modes used in the study}

\begin{tabular}{|c|c|}
\hline ID & Failure mode description \\
\hline 1.1 & Pipe plugging \\
\hline 2.1 & Pipe breakage \\
\hline 3.1 & Pump breakage causes tailings spill \\
\hline 3.2 & Pump breakage causes explosion \\
\hline 4.1 & Dam liquefaction - dam slumping \\
\hline 4.2 & Dam liquefaction - dam liquefaction and flow for a short distance \\
\hline 4.3 & Dam liquefaction - dam and tailings liquefaction and flow for a long distance \\
\hline 5.1 & Slumping or toe failure - dam slumping \\
\hline 5.2 & Slumping or toe failure - dam liquefaction and flow for a short distance \\
\hline 5.3 & Slumping or toe failure - dam and tailings liquefaction and flow for a long distance \\
\hline 6.1 & Failure of exposed tailings face \\
\hline 7.1 & Overtopping - dam slumping \\
\hline 7.2 & Overtopping - dam liquefaction and flow for a short distance \\
\hline 7.3 & Overtopping - dam and tailings liquefaction and flow for a long distance \\
\hline 8.1 & Seepage \\
\hline 9.1 & Dust generation \\
\hline 10.1 & Operation failure \\
\hline 11.1 & Underflow exit plugging \\
\hline 12.1 & Overtopping \\
\hline 13.1 & Rakes jamming or breakage \\
\hline
\end{tabular}

The following figures show the comparison of scenario 1 and scenario 2 in terms of the risks (low, medium or high) for each of the failure modes included in the study.

Figure 5 shows the comparison between scenario 1 and 2 for the risk of environmental consequences of failures regarding pipeline transportation and pumping during operation stage. As can be seen in the figure, the paste system has greater risk of environmental impacts than conventional tailings for all the failures associated with pipeline transportation and pumping during the operational stage. And for both of the scenarios, there are fewer risks of environmental effects for pump breakage than other failures. 


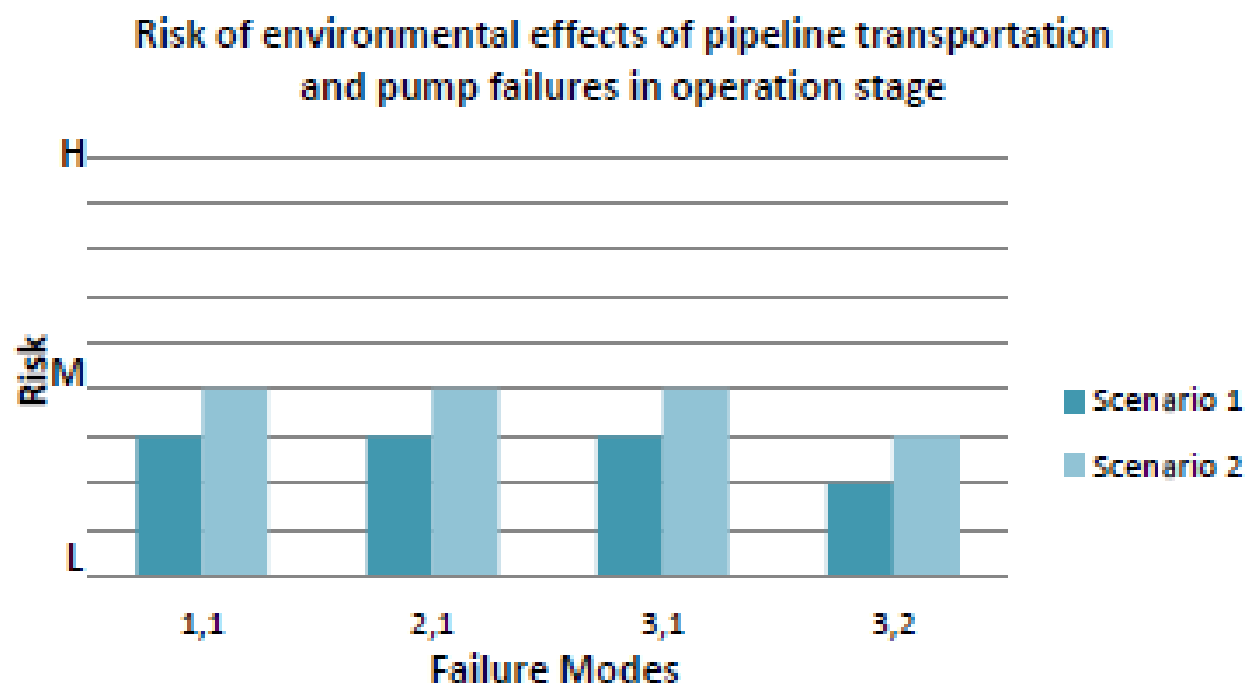

Figure 5 Risk of environmental effects of pipeline and pump failures in the operational stage

Figure 6 shows the risks for public safety impacts of failure of pipeline and pumps for scenario 1 and 2 in the operational stage. The conventional tailings scenario has a lower risk of public safety impacts than paste for all of the failure modes.

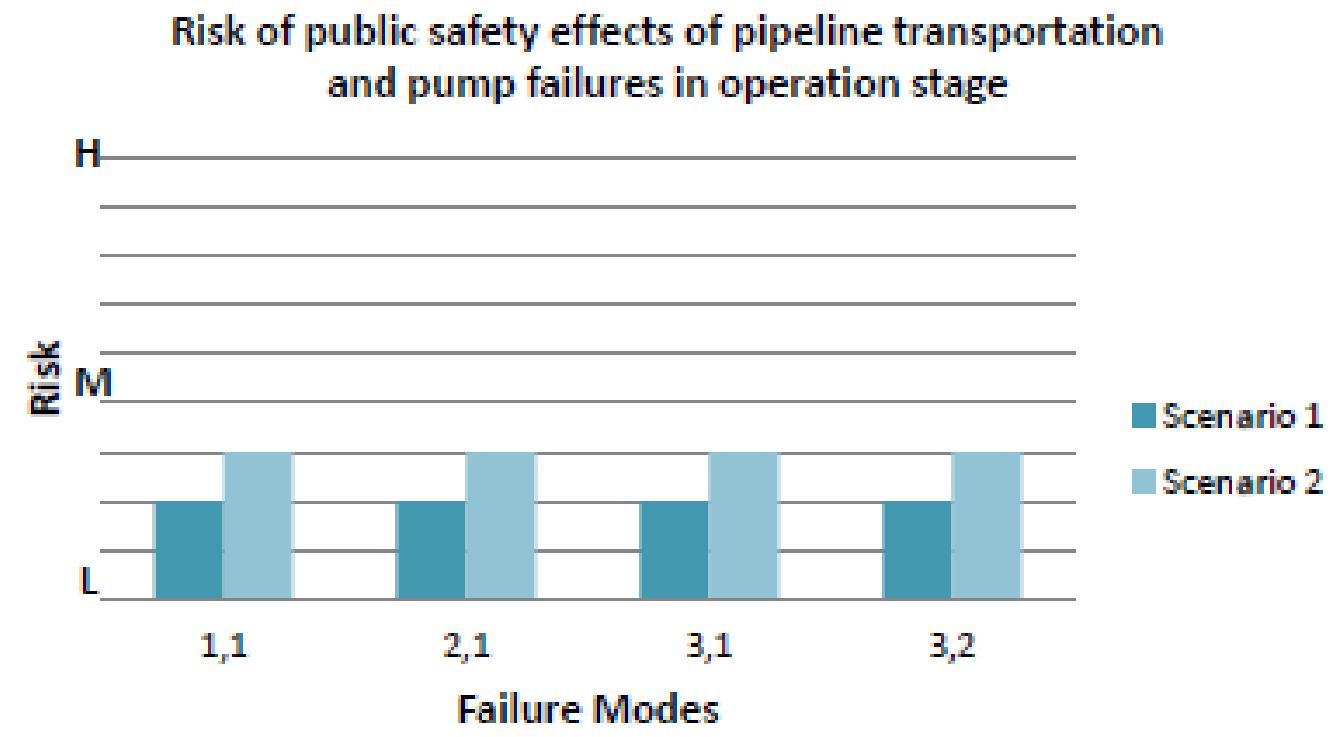

\section{Figure 6 Risk of public safety effects of pipeline and pump failures in the operational stage}

Figure 7 shows the risk of environmental impacts of the tailings storage failures for scenario 1 and 2 during the operational stage. As is shown by the figure, the conventional wet tailings facility has a higher risk of environmental impact than paste for all the failure modes except dust generation, in which both have a similar risk of environmental impacts. 


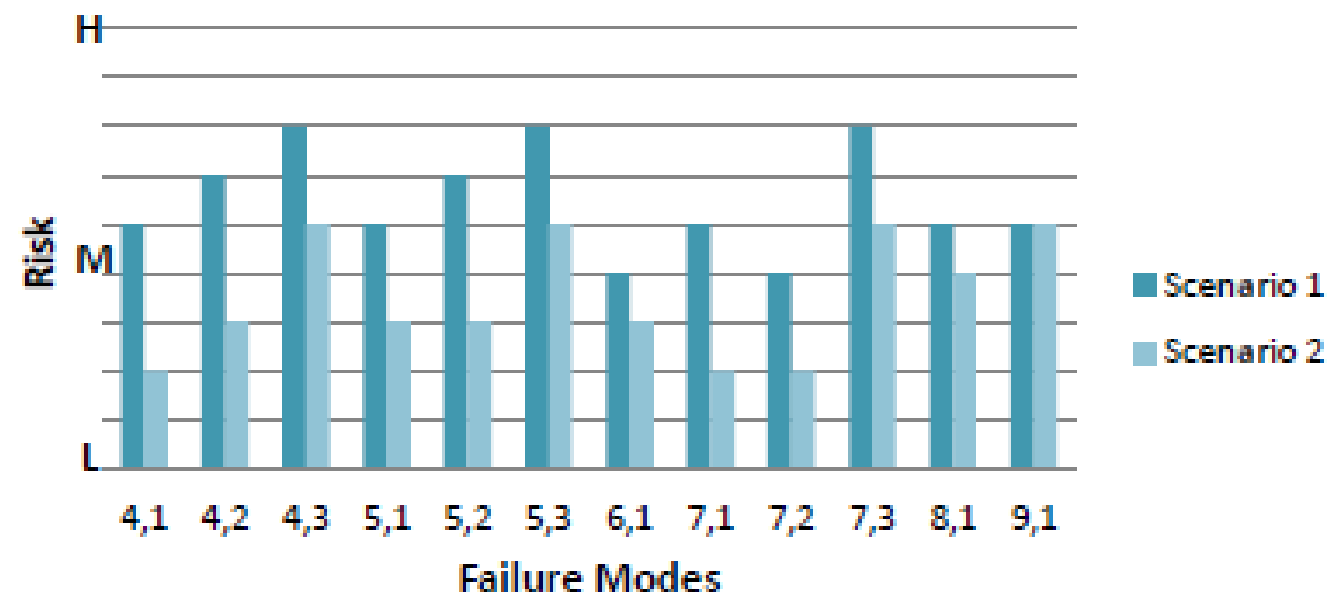
Figure 7 Severity of environmental impacts of failure of dam during the operational
stage

Figure 8 shows the risk of public safety impacts associated with failure of the storage facility during the operational stage. Conventional tailings facility has a higher risk of public safety impacts than paste for all the failures except dust generation for which both have similar risks.

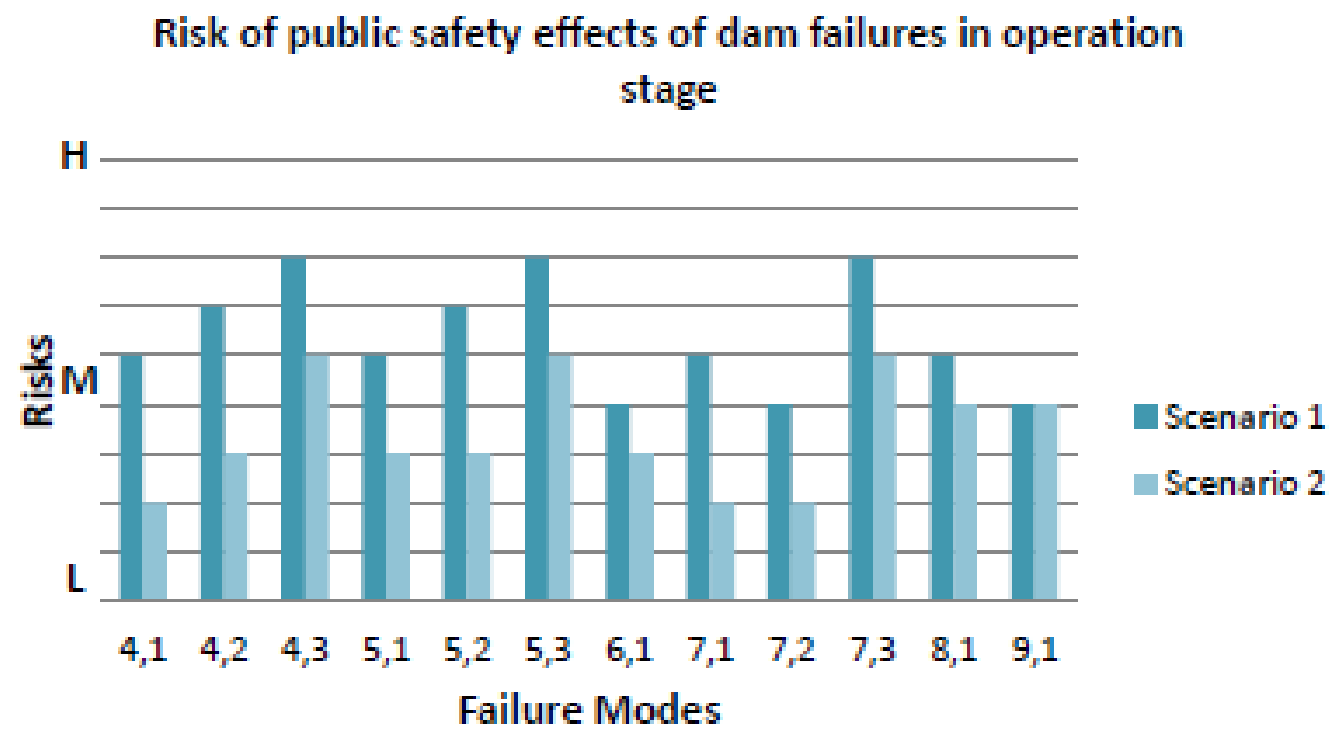

Figure 8 Risk of public safety effects of dam failures in the operational stage

Figure 9 shows the risk of environmental impacts associated with failure of the storage facility during the post-closure stage. Post-closure, conventional tailing facilities have a higher risk of public safety impacts than paste systems for all of the failure modes except dust generation. 
Risk of environmental effects of dam failures in post closure stage

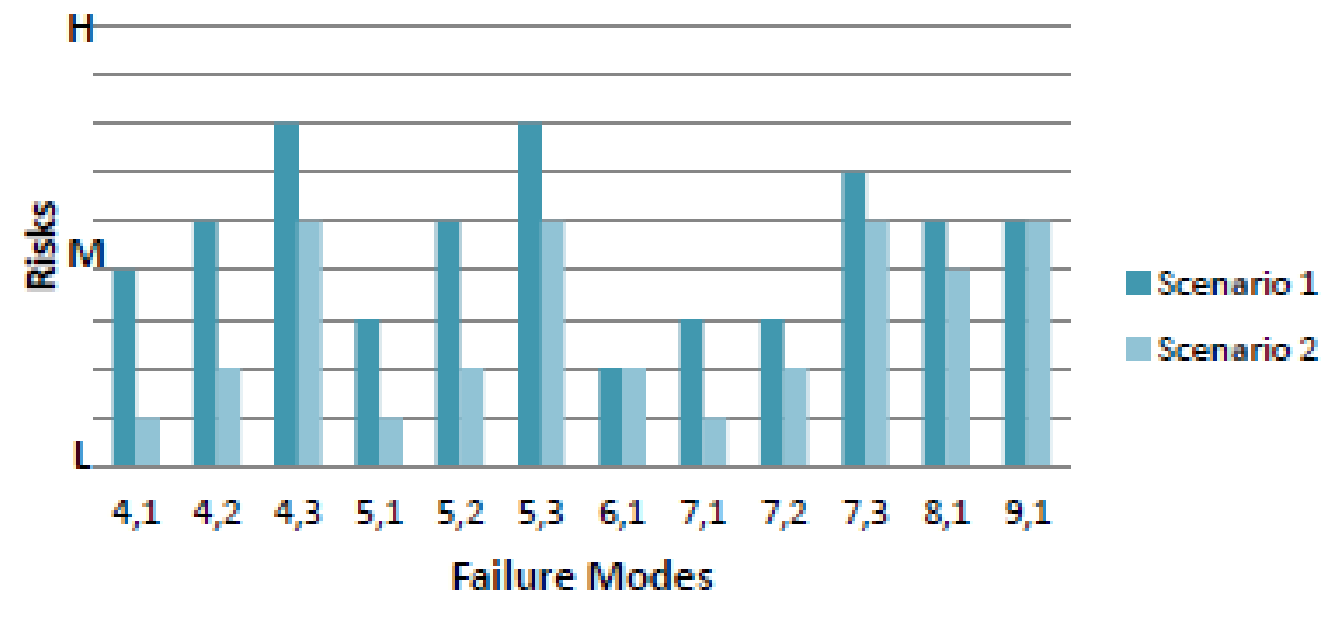

Figure 9 Risk of environmental effects of dam failures in the post-closure stage

Figure 10 shows the risk of public safety impacts associated with tailings storage facility failure during the post-closure stage. As for the environmental impacts, conventional tailing dams have a higher risk of public safety impacts than paste systems for all of the failure modes except for the dust generation.

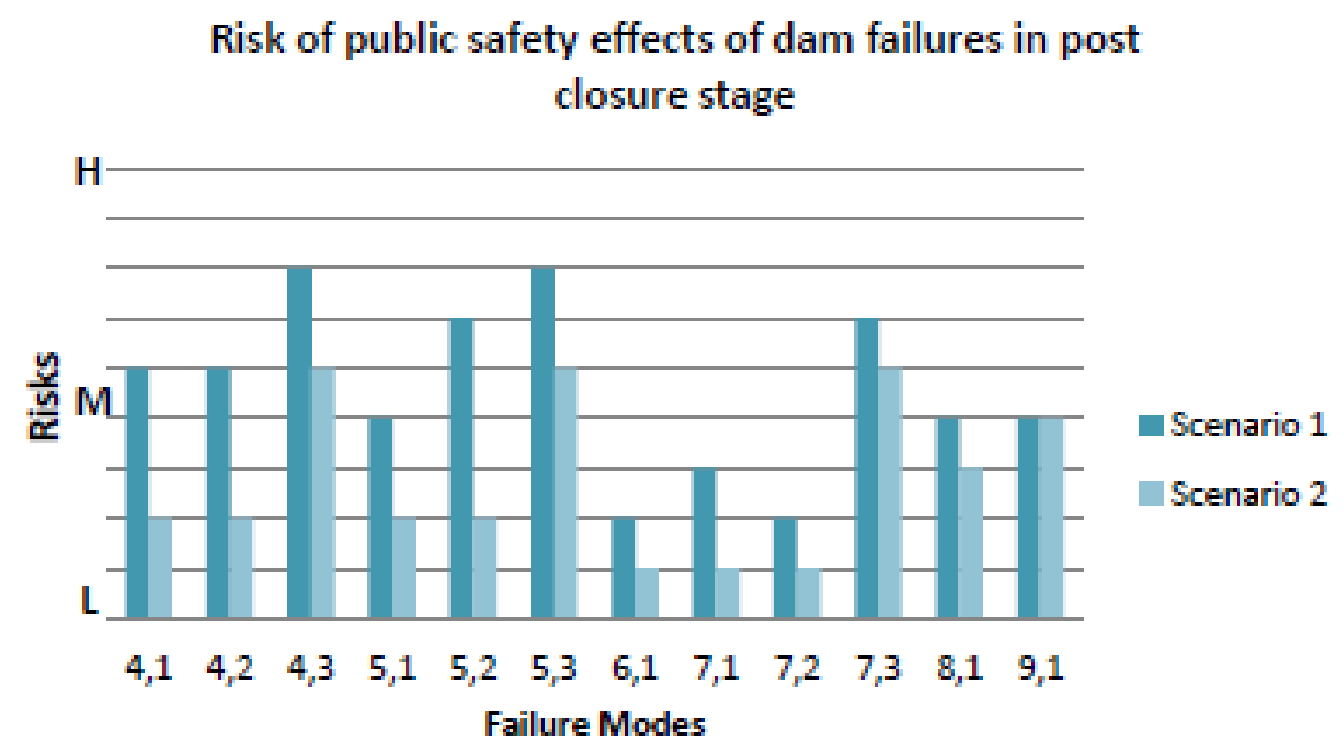

Figure 10 Risk of public safety effects of dam failures in the post-closure stage

Figure 11 shows the risk of environmental and public safety impacts for the thickener during the operational stage. The thickener has relatively low risk for both environmental and public safety impacts for the paste option. In conventional wet tailing systems there is no paste thickener installed, hence a comparison cannot be made. 
Risk of environmental effects and public safety effects of thickener in operation stage

H

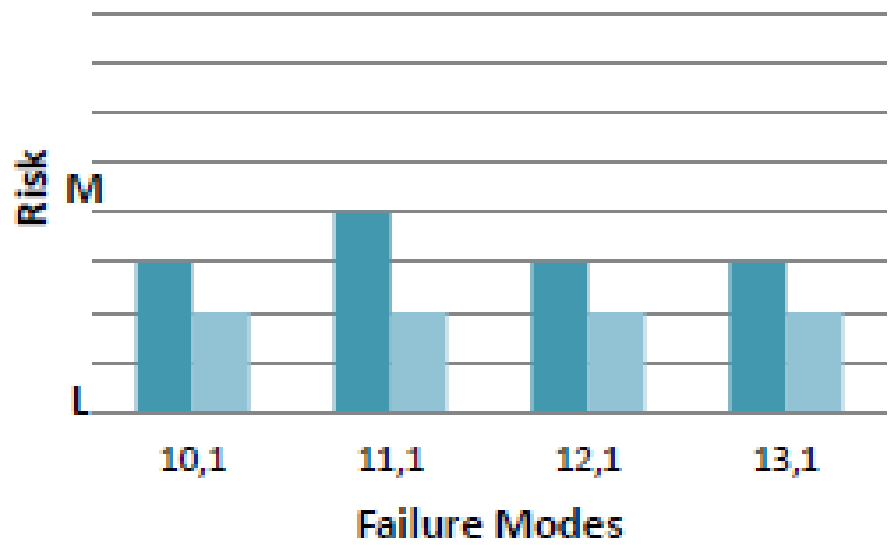

Environmental effects

Public safety

Figure 11 Risk of environmental effects and public safety effects of thickener in the operational stage

Figures 12 and 13 illustrate the risk distribution for environmental and public safety impacts for both scenarios. The number of failures in each risk category used in the matrix is shown. The risks are labelled from $\mathrm{L}$ to $\mathrm{H}$, and it is clear from the figures that most of the failures of the paste tailings system are rated as low to middle levels risks, while most of the conventional tailings system risks have upper middle level ratings.

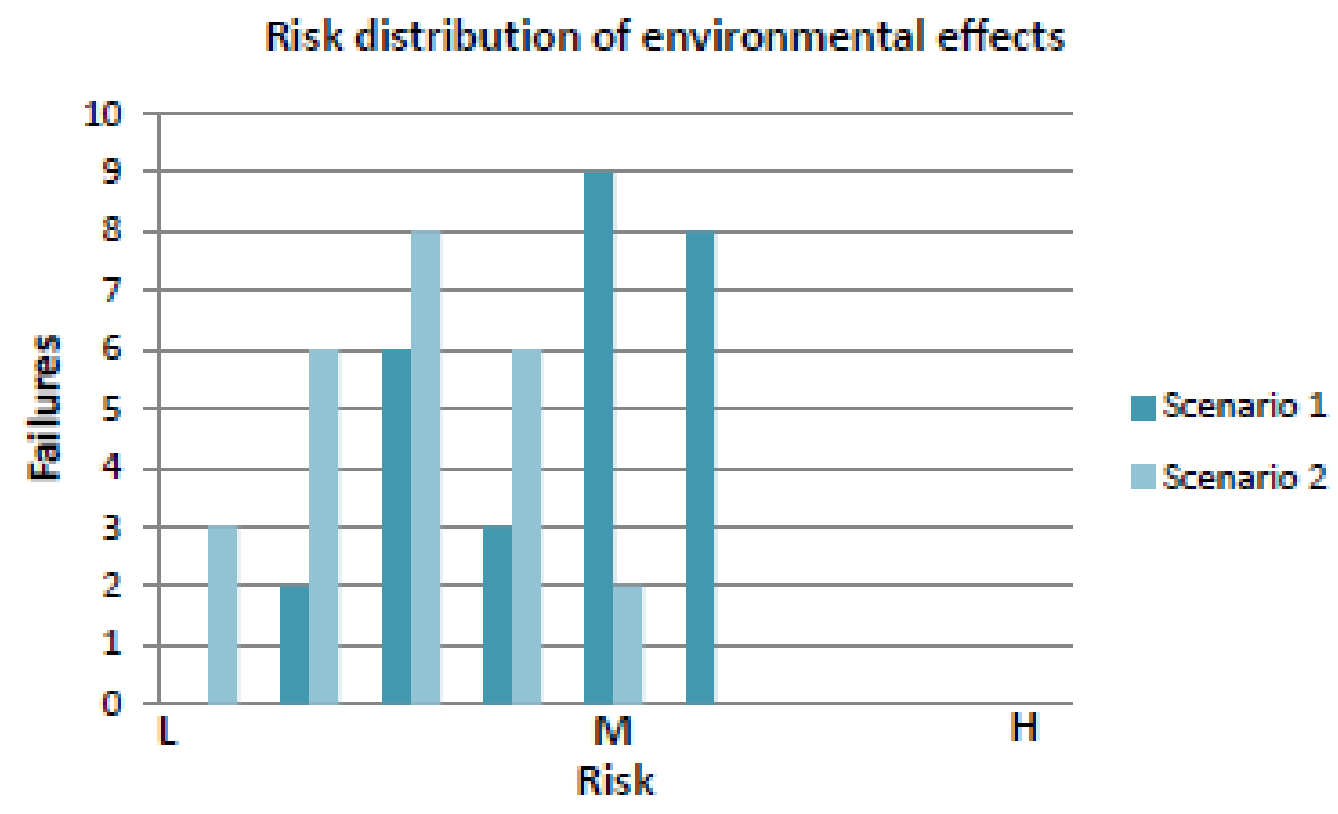

Figure 12 Risk distribution of environmental impacts 


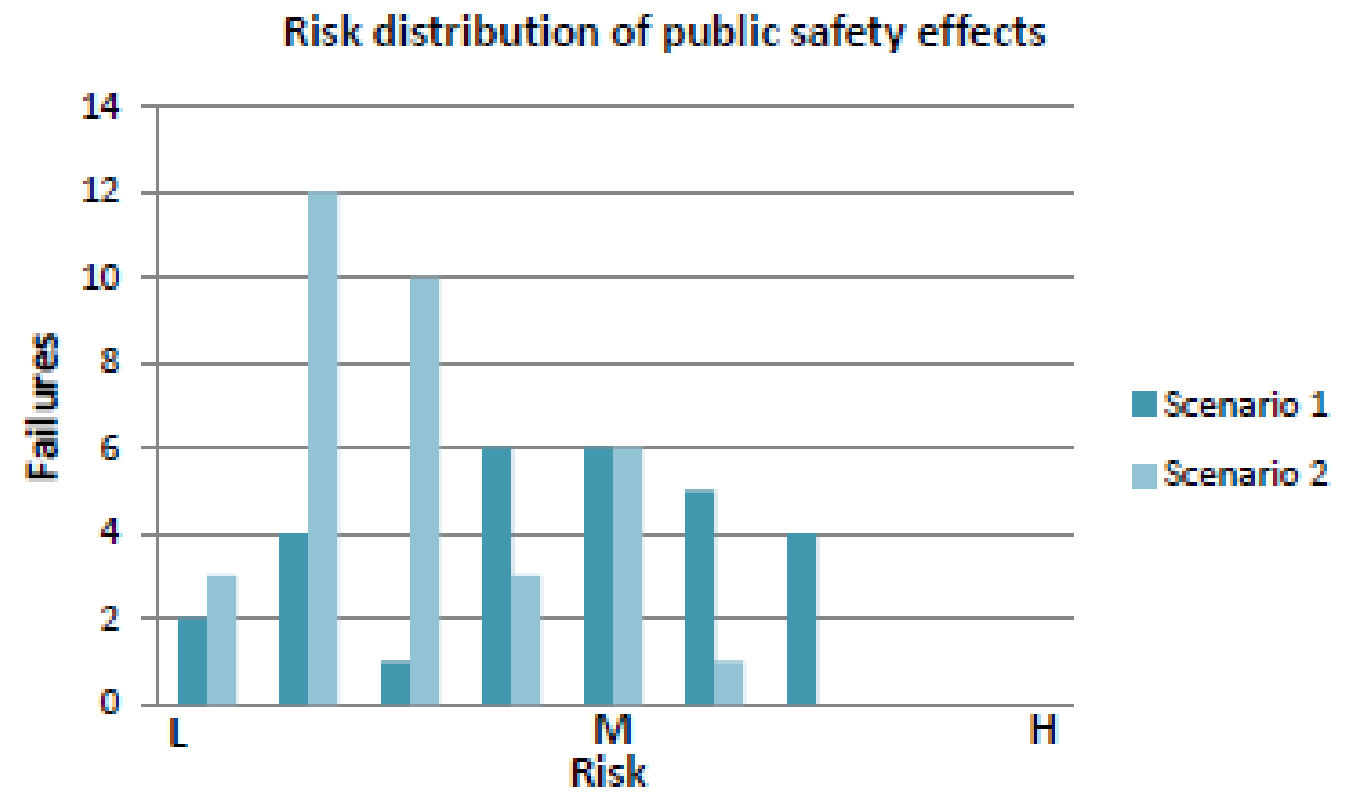

Figure 13 Risk distribution of public safety impacts

\section{Conclusions}

In summary, the main problems that impact the sustainability of mining operations regarding tailings are derived from the failure of storage facility and associated infrastructure. The main differences between the risks of for conventional tailings disposal and paste tailings disposal are:

- Paste tailings systems have a low risk of environmental and public safety impacts associated with thickener failure in the operational stage.

- Paste tailings systems have a higher risk of environmental and public safety impacts associated with the transportation system failures in the operational stage.

- Conventional tailings systems have a higher risk of environmental and public safety impacts associated with failure of the storage facility than paste facilities except for the dust generation in both the operational and post-closure stages.

- Conventional tailings and paste tailings have similar environmental and public safety risks associated with dust generation in both the operational and post-closure stages.

It is concluded that paste tailings systems provide a more sustainable solution than conventional wet tailings systems. Although paste systems have higher risks associated with the transportation and thickening infrastructure in the operational stage, they have much lower risk of failure of the storage facilities both the operational and post-closure stages. The tailings storage is the only part of the mine infrastructure that is likely to remains behind after mine closure. Hence, it is the origin of impacts to the environment and public safety for a long period of time. This study, which considers the impacts of tailings in 100 years after the post-closure, qualitatively demonstrates that paste tailings are more sustainable.

\section{References}

Aguilar, J, Dorronsoro, C, Fernández, E, Fernández, J, García, I, Martín, F, Ortiz, I \& Simon, M 2000, El desastre ecológico de Aznalcóllar, Universidad de Granada, viewed 20 September 2014, http://edafologia.ugr.es/donana/aznal.htm

Davies, M, Martin, T \& Lighthall, P 2000, 'Mine tailings dams: when things go wrong', Proceedings of Tailings Dams 2000, Association of State Dam Safety Officials, U.S. Committee on Large Dams, pp. 261-273.

Department of Resources Energy and Tourism (RET) 2008, Risk assessment and management, RET, Canberra.

Department of Resources Energy and Tourism (RET) 2007, Tailings management, RET, Canberra.

Doka, G 2009, Life cycle inventory data of mining waste: emissions from sulfidic tailings disposal, Doka Life Cycle Assessments, Zürich. 
Dold, B 2008, 'Sustainability in metal mining: from exploration, over processing to mine waste management', Reviews in Environmental Science and Bio/Technology, vol. 7, no. 4, pp. 275-285.

Engels, J 2013, Conventional impoundment storage - the current techniques, University of Leeds, viewed 09 September 2014, http://www.tailings.info/disposal/conventional.htm

European Neighbourhood Partnership Instrument (Eastern Region) [ENPI East] 2011, Waste governance - ENPI East: methodology for the environmental \& health risk assessment of mine tailings disposal sites, ENPI East, Kyiv.

International Commission on Large Dams (ICOLD) \& United Nations Environmental Programme (UNEP) 2001, Bulletin 121: tailings dams - risk of dangerous occurrences, lessons learnt from practical experiences, ICOLD \& UNEP, Paris.

Rausand, M, \& Høyland, A 2003, System reliability theory: models, statistical methods, and applications, Wiley-Interscience, Hoboken.

RET 2007, 'Tailings management', Canberra Australia Government, Commonwealth of Australia.

Robertson, MG \& Shaw, S 2003, Risk management for major geotechnical structures on mines, Robertson GeoConsultants Inc., Vancouver, viewed 11 March 2015, www.rgc.ca/files/publications/cami03risk.pdf

Robinsky, El 1999 'Tailings dam failures need not be disasters: the thickened tailings disposal (TTD) system', CIM Bulletin, vol. 92 , no. 1028 , pp. $140-142$.

Sachan, C 2010, 'New Directions in Tailings Management', in The Organizing Committee of the 14th International Conference on Tailings and Mine Waste, Proceedings of Tailings and Mine Waste, pp. 41-48.

Standards Australia 2004, AS/NZS 4360:2004 Risk Management, Standards Australia, Sydney.

Wennberg, T 2010, 'Transporting highly concentrated slurries with centrifugal pumps: the thickened minerals tailings example', Licentiate thesis, Luleå tekniska universitet, Luleå. Licentiate thesis / Luleå University of Technology.

Xenidis, A, Papassiopi, N \& Komnitsas, K 2003, 'Carbonate-rich mining tailings in Lavrion: risk assessment and proposed rehabilitation schemes', Advances in Environmental Research, vol. 7, no. 2, pp. 479-494.

Xin, Z, Xiaohu, X \& Kaili, X 2011 'Study on the risk assessment of the tailings dam break', Procedia Engineering, vol. 26, pp. 2261-2269. 